\title{
DISCURSO DE HOMENS SOBRE O ACESSO À SAÚDE NA ATENÇÃO BÁSICA
}

\author{
DISCOURSE OF MEN ABOUT ACCESS \\ TO HEALTH IN PRIMARY HEALTHCARE
}

\section{EL DISCURSO DE HOMBRES SOBRE EL ACCESO A LA SALUD EN LA ATENCIÓN PRIMARIA}

\author{
Bruno Dias Batista ${ }^{1}$ \\ Mayara Evangelista de Andrade ${ }^{2}$ \\ Marília Moreira Torres Gadelha ${ }^{1}$ \\ Jéssica Mayara Almeida Silva ${ }^{3}$ \\ Petra Kelly Rabelo de Sousa Fernandes ${ }^{4}$ \\ Marcelo Costa Fernandes 5
}

Como citar este artigo: Batista BD, Andrade ME, Gadelha MMT, Silva JMA, Fernandes PKRS, Fernandes MC. Discursos de homens sobre o acesso à saúde na Atenção Básica. Rev baiana enferm. 2019;33:e29268.

Objetivo: conhecer os discursos de homens sobre o acesso à saúde na Atenção Básica. Método: estudo descritivo, realizado em dezembro de 2016 com 20 usuários da Atenção Básica do município de Cajazeiras, Paraíba, Brasil. Adotou-se como recurso metodológico a Análise de Discurso. Resultados: dos discursos emergiram as categorias: dificuldade em discernir as funções da Atenção Básica; exaltação do modelo biomédico; prática da medicalização; fatores de afastamentos do serviço; ausência de ações e programas destinados aos homens; e divergência entre masculinidade e feminilidade. Conclusão: os discursos masculinos ratificaram a necessidade de reorientação de saberes e práticas dos serviços de saúde para ampliar o acesso da população masculina na Atenção Básica.

Descritores: Atenção Primária à Saúde. Masculinidade. Gênero. Saúde do Homem.

Objective: getting to know the discourses of men about the access to bealthcare in Primary Healthcare. Method: descriptive study carried out December 2016 with 20 users from the Primary Healthcare of the city Cajazeiras, Paraiba, Brazil. The Discourse Analysis was the methodological resource adopted. Results: the following categories emerged from the discourses: difficulties in discerning the functions of Primary Healthcare; praise for the biomedical model; practice of medicalization; factors related to service leave; absence of actions and programs destined to men; and differences between masculinity and femininity. Conclusion: male discourses ratified that knowledge and practices of health services need to be re-oriented to broaden the access of the male population to Primary Healthcare.

Descriptors: Primary Health Care. Masculinity. Gender. Men's Health.

\footnotetext{
Enfermeiro. Pesquisador independente. Cajazeiras, Paraíba, Brasil. https://orcid.org/0000-0002-907 I-7026; https://orcid.org/0000-000 I-9842- I I69

Enfermeira. Especialista em Enfermagem Obstétrica e em Docência do Ensino Superior. Pesquisador independente. Cajazeiras, Paraíba, Brasil. https://orcid.org/0000$0001-5256-2169$

3 Enfermeira. Especialista em Saúde Coletiva com Ênfase em Saúde da Família. Pesquisador independente. Cajazeiras, Paraíba, Brasil. https://orcid.org/0000-000 I8727-508X

4 Enfermeira. Mestre em Cuidados Clínicos. Professora de Enfermagem da Faculdade Metropolitana da Grande Fortaleza. Universidade Estadual do Ceará. Fortaleza, Ceará, Brasil. https://orcid.org/0000-0002-479|-5676

5 Enfermeiro. Doutor em Cuidados Clínicos em Saúde. Professor da Universidade Federal de Campina Grande. Campina Grande, Paraíba, Brasil. celo_cf@hotmail.com
} 
Objetivo: conocer los discursos de hombres sobre el acceso a la salud en la Atención Primaria. Método: estudio descriptivo realizado con 20 usuarios de la Atención Primaria de la ciudad de Cajazeiras, Paraíba, Brasil, en diciembre 2016. El Análisis del Discurso fue el recurso metodológico adoptado. Resultados: las siguientes categorías emergieron de los discursos: dificultad en reconocer las funciones de la Atención Primaria; exaltación del modelo biomédico; práctica de medicalización; factores de distanciamiento del servicio; ausencia de acciones y programas destinados a los hombres; y diferencias entre masculinidad y feminidad. Conclusión: los discursos masculinos ratificaron que es necesario reorientar saberes y prácticas de los servicios de salud para ampliar el acceso de la población masculina a la Atención Primaria.

Descriptores: Atención Primaria de Salud. Masculinidad. Género. Salud del Hombre.

\section{Introdução}

A atenção à saúde do homem vem tornando-se parte das ações promovidas pela Atenção Básica (AB), o que proporciona ampliação de discussões acerca dessa recente ótica. Entretanto, apesar desse relativo avanço, fragilidades ainda são notadas nas ações de saúde ofertadas a esse público, principalmente em decorrência da falta de compreensão de cuidados específicos para esses atores sociais.

O fato de as necessidades desse público muitas vezes não serem reconhecidas nos serviços de saúde da $\mathrm{AB}$ resulta numa parcela da população excluída da rotina da assistência. Tal conjuntura acaba por fomentar a procura dos serviços de saúde pelos homens apenas quando surgem agravos e doenças previamente instalados, em especial em situações de emergência e/ou urgência, o que demanda cuidados especializados e de alta complexidade ${ }^{(1-3)}$.

Ressalta-se também que a construção desigual de gênero, que alimenta a crença social de que homens são mais fortes que mulheres e consequentemente não adoecem e não necessitam de cuidados, interfere no acesso deles aos serviços de saúde ${ }^{(4)}$. Isso explica os altos índices de morbimortalidade e agravos dos homens em relação às mulheres ${ }^{(5)}$.

Diante dessa perspectiva, o Ministério da Saúde implantou, em 27 de agosto de 2009, a Política Nacional de Atenção Integral à Saúde do Homem (PNAISH) ${ }^{(6)}$, que visa reconhecer a necessidade de integralidade do indivíduo mediante sua representação no cenário da $\mathrm{AB}$ e reduzir os fatores de risco responsáveis pelos altos índices de mortalidade e morbidade dos homens. Essa política atua nas questões de concepção de gênero, com a finalidade de proporcionar melhores condições de saúde para esse público.

As discussões a respeito da saúde do homem refletem a extrema necessidade de busca por melhorias na validação de preceitos revigorados pela PNAISH. A inserção desse público nas ações de cuidados implica, direta e positivamente, na modificação dos indicadores de morbimortalidade, na significação de gênero que vigora na sociedade histórica e culturalmente.

A relevância do estudo reside no fato de suscitar a necessidade de se trabalhar a atenção integral à saúde do homem em conjuntura capaz de atrair o contingente masculino para o cenário de saúde, apoiado pelo envolvimento do serviço, da gestão, do ensino e da pesquisa, incentivando explanações que visem sanar ou minimizar essa problemática.

Nesse sentido, emerge a questão norteadora desta pesquisa: Quais os discursos dos homens sobre o acesso à saúde no âmbito da Atenção Básica? O estudo objetiva conhecer os discursos de homens sobre o acesso à saúde na Atenção Básica.

\section{Método}

Trata-se de estudo descritivo, com abordagem qualitativa, realizado com 20 usuários da Atenção Básica do município de Cajazeiras, Paraíba, Brasil. A coleta de dados, realizada no mês de dezembro de 2016, deu-se por meio de entrevista semiestruturada, que ocorreu em 
local reservado do próprio serviço de saúde. Adotou-se como critério de inclusão a participação dos homens que estavam cadastrados pelo menos há um ano na Estratégia de Saúde da Família (ESF). Estabeleceu-se como critério de exclusão, homens que buscavam o serviço como acompanhantes de outros usuários.

As informações coletadas por este estudo foram examinadas à luz da Análise de Discurso (AD). Esta vertente interpretativa viabiliza melhor compreensão do homem, enquanto indivíduo possuidor da capacidade de promover significado e de significar-se ${ }^{(7)}$. A AD apresenta características consistentes como forma interpretativa dos dados, capaz de atender ao objetivo da pesquisa e buscar os sentidos produzidos e imersos no contexto sócio-histórico, desenvolvendo-se em três etapas: passagem da superfície linguística para o objeto de discurso; passagem do objeto discursivo para o processo discursivo; e passagem do processo discursivo para a formação ideológica ${ }^{(7)}$.

O anonimato dos participantes foi mantido com o uso de códigos alfanuméricos constituídos pela letra $\mathrm{H}$, de homem, seguido de um algarismo arábico. O estudo teve início após aprovação do projeto pelo Comitê de Ética em Pesquisa da Universidade Federal de Campina Grande, campus Cajazeiras, sob Parecer $\mathrm{n}^{\mathrm{o}}$ 1.844.255. Os princípios éticos que regem as fases do estudo apresentam consonância com a Resolução $n^{\circ} 466 / 2012$, do Conselho Nacional de Saúde ${ }^{(8)}$.

\section{Resultados}

As representações enunciativas compreendidas neste estudo têm seus alicerces fincados nas formações discursivas elucidadas, que confluem para uma formação ideológica que atua como pano de fundo e base dos discursos dos atores sociais. Forjado em tais representatividades, o modelo biomédico revoga o princípio gerador e estruturador de práticas voltadas ao adoecimento e ao sujeito enquanto objeto. Aliado a essa conjuntura, é perceptível, nos discursos, a compreensão dos usuários a respeito da função da AB para o público masculino:

Rapaz, eu acho muito bom o posto aqui, é bem atendido
[Quem são bem atendidos? Os homens? As mulheres?]
A pessoa chega faz a ficha é bem atendido, não tenho o
que falar do posto não. É... eu acho o posto muito bom e
nota dez pra eles. (H3).

A gente vem aqui no posto. Eu não tenho do que reclamar coisissima nenbuma. Não tenho do que reclamar não. Olha, já fui atendido. (H5).

Nota-se a presença de uma polissemia, que manifesta a contradição em torno do entendimento acerca do cenário que compõe a $\mathrm{AB}$ para o segmento masculino.

É pra prevenir alguma doença, né? Na verdade, eu visito muito o posto de saúde nos últimos seis anos. Nesse aqui mesmo, eu já vim umas dez vezes. (H10).

Pros homens? Eu acho que não só pros homens, mas para todos é auxiliar, né? Uma instituição que dá suporte para as demais, no caso, por exemplo, a UPA. Ai vai um atendimento mais de urgência; aqui vai um atendimento mais pra aferir pressão, esse tipo de procedimento mais simples. É isso que eu entendo, né? (H14).

No transcorrer desta investigação, ficou evidente a repetida explanação, ancorada em discursos parafrásticos e, por vezes, de cunho metafórico, do cenário da $\mathrm{AB}$ como espaço de assistência nos casos de agravamento da saúde. A busca por métodos alternativos foi citada como justificativa para a não procura por atendimento.

[...] Deus me ajuda. E mais, eu me preocupo mais com os outros. Aí é esse caso que às vezes eu não gosto muito de ir no postinbo de saúde. Tomo logo um comprimido pra dor de cabeça, tomo. Uma vez uma simpatia pra dor de cabeça passou na televisão, pra enxaqueca, né? Pra tomar o caldo de feijão insosso três sexta-feira. Ab! Eu queria, eu fiz. (H17).

Rapaz, aí quando tem um caso maior, né? [Quais seriam esses casos?] Um problema maior de saúde. Quando é uma coisa pequena a gente se rebola. Quando é maior, por causa de negócio de pressão, que o médico tem que olhar, né? [...] Se rebola é, a pessoa evitar de tá no pé do médico, vai tomando um remédio, uma outra coisa, né? Pra não tá sempre no pé do médico. Sempre no pé do médico é bom, mas diz que é bom, mais quando não procura o médico, às vezes aparece um problema de saúde maior, né? Aí o caba [a pessoa] vai cuidar e já é tarde. Que o meu jeito toda vida é esse, né? Nunca gostei de tá em pé de médico. (H16).

Os discursos dos participantes denotam a ressonância de fatores que interferem diretamente em sua procura pelo serviço. 
O que me incomoda é a demora. Aquela espera. Bote tempo, o caba [a pessoa] toma um chá de gelo. Se o caba [a pessoa] não esperar, dá vontade de ir embora. (H4).

É o tempo, também o trabalho, o trabalbo também e o caba [a pessoa] que num liga não tem... Deixa pra lá as coisa [a saúde], né? Só vem quando acontece a doença, quando tá passando mal. (H9).

Entremeado a essa problemática prepondera, na presente pesquisa, a falta de ações direcionadas ao público masculino, o que interfere diretamente na acessibilidade e na presença dessa parcela populacional nesse campo de assistência.

\begin{abstract}
Eu acho que é pouca. É... acho que se for de cem por cento, noventa é mulher. É que é as mais necessitadas [Porque as mulheres são mais necessitadas? E os homens, não desfrutam das mesmas necessidades?] É quem procura mais as unidades de saúde é as mulberes. Nós bomens dificilmente. A gente procura, e quando procura não tem o que a gente quer. Às vezes um remédio, um negócio. Ai tem que tirar do bolso, às vezes sem nem poder. Tirar da goela, da boca do filbo, dum negócio, duma feira, do gás, bujão, pra poder se manter. Porque o governo não oferece uma boa saúde. (H2).
\end{abstract}

Rapaz é mais essa daí o da próstata, né? Aquela velha catarata que tem nessas ações. O vírus da AIDS, a tuberculose, só. (H4).

Há de se considerar a divergência entre masculinidade e feminilidade, a qual ganha destaque no segmento de saúde e nas relações e conotações de gênero interpostas, configurando a ausência do masculino na unidade de saúde.

A mulher é mais bem-atendida [Por que é melhor atendida?] Sempre, em todo canto, mulher tem privilégio [Quais seriam esses privilégios disponíveis para as mulheres?] E nos postos de saúde principalmente. Assim, vamos supor... O tratamento fosse igual da mulher, mais para o homem [O que deveria ser igual no atendimento?] Porque sempre tem aquele probleminha [Qual problema?] porque... Mudasse, né? Esse clima [Qual clima?] né? Homem, mulher. Que todo mundo trate, todo mundo igual, da mesma forma. O tratamento ótimo. É que nem diz: remédio, na hora que você chegar, fazer a sua fichinha, for atendido, tomar aquela medicação na bora certa. Mas, é muito difícil a gente encontrar isso. (H2).

\section{Discussão}

Os discursos permitem a apreensão do sentido que os homens atribuem à $\mathrm{AB}$, como decorre sua relação com esse serviço e quais ações permitem o envolvimento desse segmento populacional no ambiente de saúde. A explanação permite mostrar os resultados possuidores de um epicentro comum: a subversão do modelo higienista nos discursos.

Como característica inicial, emerge a visão restrita acerca dos princípios que corroboram a função da $\mathrm{AB}$ no setor saúde ${ }^{(3-4,9)}$, visto que o serviço acaba não sendo compreendido pela população como recurso de primeira instância. Contudo, pesquisadores afirmam sua especificidade como primeiro local de atendimento e apoio populacional, além de sua capacidade resolutiva da grande demanda de saúde ${ }^{(10)}$. Fundamenta-se, ainda, a base do fluxo de atendimento em rede, assim como a complexidade das atividades que comporta cada um dos cenários de atenção à saúde ${ }^{(10)}$.

Mesmo como prenúncio de compreensão quanto ao serviço, ocorrem ressonâncias do paradigma médico biológico na percepção social da saúde e da $\mathrm{AB}$, remontando a essa cadeia assistencial que ainda reverbera e interfere na visão e formulação do conceito que se obtém a respeito das práticas de cuidados. Desse modo, o modelo biomédico tradicional tem demarcações centrais na unicausalidade do processo saúde e adoecimento, promulgando um serviço enraizado na fragmentação, prescrição, reducionismo e enfoque curativista do aspecto da saúde ${ }^{(11)}$.

O foco do modelo biomédico está direcionado à prevalência de uma eficiência técnica anteposta a uma prática terapêutica que responda às demandas apresentadas ${ }^{(12)}$. Nessa corrente tradicional, prevalece a ótica mecanicista, na qual o corpo é tratado com objetividade prática e de estudo, apresentando solidez em um "abraço" que envolve e domestica o homem, condicionando uma determinada postura desses, dos profissionais e da gestão frente às ações e aos serviços a serem ofertados a esse público.

Ancorados nessa concepção ocorrem reflexos quanto à presença e/ou procura do serviço pela população masculina. Emerge, nesse cenário, uma dialogicidade de métodos que justifica a ausência desse homem do espaço de saúde, como se observa nos relatos em que recorrem a outros meios de busca por saúde. Esses estruturam o ideal de cura também por meio de recomendações não profissionais, remontando a outros 
recursos que materializam seu distanciamento do serviço e que, em seu imaginário, ecoam com o mesmo efeito que poderiam obter com a ajuda profissional. Em consonância com este resultado, estudo constatou que os participantes utilizavam chás e a automedicação como recursos alternativos para não buscarem atendimento de saúde ${ }^{(4)}$.

Desse modo, alerta-se que os homens preferem outros serviços de saúde, dentre os quais estão compreendidos: pronto-atendimento, farmácias e prontos-socorros ${ }^{(13-14)}$. Estes correspondem de maneira objetiva às suas demandas, sendo atendidos com rapidez quando se trata de problemas de fácil resolubilidade.

Observa-se que o tempo, a demora e o trabalho apresentam interferência direta na presença desse público no cenário do cuidar. Salienta-se a dificuldade desses indivíduos de buscar os serviços, ocorrendo apenas quando os sinais e os sintomas tendem a se agravar e a comprometerem suas atividades de vida diária ${ }^{(14-15)}$. Autores elencam outros elementos que se interpõem nesse quadro, tais como: horário de atendimento, falta de vagas, ausência de exames, dificuldades de atendimento e grandes filas ${ }^{(16-17)}$.

Apreende-se, com base nos discursos, que os participantes externam o (des)conhecimento da existência de ações que assegurem intervenções no campo da saúde do homem. Isso é percebido quando mencionam outros programas e ações ministeriais, nos quais a singularidade e a representatividade masculina não são evidenciadas e/ou centralizadas ${ }^{(17)}$. O fato de os participantes não conseguirem retratar as ações ofertadas ao público específico reflete seu afastamento dos serviços. Afinal, o atendimento voltado aos homens, muitas vezes, não faz parte do cronograma de atividades diárias na $\mathrm{AB}$, tendo como norteamento de atendimento os ciclos de vida e as condições/estado de saúde do indivíduo ${ }^{(17)}$.

Nessa mesma perspectiva, destaca-se, nas falas dos sujeitos, a exaltação da mulher como ser que necessita de maior cuidado, ressaltando o simbolismo da fragilidade de gênero. O aprofundamento dos discursos mostra a existência de uma relação histórico-dialética reiterada em relação ao estigma social enraizado na concepção masculina. Isso é percebido ao longo dos discursos, quando outros programas e ações ministeriais acabam sendo descritos, nos quais a singularidade masculina não é evidenciada.

Compreender os modelos de masculinidade e feminilidade prevalentes na sociedade e nas relações de gênero potencializa as instâncias do governo em sua capacidade de produzir e implementar ações e programas no campo da saúde pública mais coadunados às formas do agir social em conformidade com as relações de gênero ${ }^{(5)}$. Outra opção, para atender a essa demanda, é a articulação, por parte de profissionais e gestores, das políticas de saúde que têm o homem como protagonista, para fomentar ações que reconheçam as especificidades desse segmento populacional, vislumbrando a integralidade da assistência a essa população ${ }^{(18)}$. Há, nesse sentido, a necessidade de desconstrução do entendimento do homem como vítima e culpado por sua doença e, por conseguinte, a urgente restruturação e organização do cenário de saúde ${ }^{(19)}$.

Ressalta-se, por fim, que, apesar da consistente permanência do modelo curativista entre os setores de saúde, a principal conjuntura, que pode ajudar a promover e/ou atrair o contingente masculino para o cenário da saúde, compreende pensar o serviço como um espaço de produção de cuidado, que possa agregar ao modelo biomédico novas possibilidades de ações e serviços e atue como eixo estruturante das tecnologias leves.

Os resultados apresentam limitações, uma vez que foi desenvolvido na ESF de apenas um município, não podendo ser generalizado, pois apresenta forte dependência da dinâmica de saúde da região estudada.

\section{Conclusão}

A análise dos discursos dos homens mostrou a necessidade de reorientação de saberes e práticas dos serviços de saúde para ampliar o acesso da população masculina no âmbito da Atenção Básica. Os aspectos que ressoam no acesso do segmento masculino ao serviço da $\mathrm{AB}$, externado 
na sua discursividade, evidenciaram as lacunas quanto à compreensão da função desse serviço de saúde, a preponderância da concepção biomédica, a busca por métodos alternativos como qualidade de saúde, a ausência de ações direcionadas ao público masculino e a conotação do processo sócio-histórico-cultural quanto à divergência de gênero no atendimento em saúde.

Destaca-se a necessidade de se trabalhar a atenção integral à saúde do homem em conjuntura capaz de atrair o contingente masculino ao cenário de saúde, de tal modo que profissionais, gestores e usuários compreendam e pensem o serviço como espaço de produção de cuidado. Importante ainda agregar novas possibilidades de ações e programas, como arcabouço de eixos estruturantes das tecnologias cuidativas e sob pressupostos que reiterem a filosofia do SUS.

\section{Colaborações:}

1 - concepção, projeto, análise e interpretação dos dados: Bruno Dias Batista, Mayara Evangelista de Andrade e Marília Moreira Torres Gadelha;

2 - redação do artigo e revisão crítica relevante do conteúdo intelectual: Jéssica Mayara Almeida Silva, Petra Kelly Rabelo de Sousa Fernandes e Marcelo Costa Fernandes;

3 - aprovação final da versão a ser publicada: Bruno Dias Batista e Marcelo Costa Fernandes.

\section{Referências}

1. Moura EC, Santos W, Neves ACM, Gomes R, Schwarz E. Atenção à saúde dos homens no âmbito da Estratégia Saúde da Família. Ciênc saúde coletiva. 2014 Feb;19(2):429-38. DOI: http:// dx.doi.org/10.1590/1413-81232014192.05802013

2. Solano LC, Bezerra MAC, Medeiros RS, Carlos EF, Carvalho FPB, Miranda FAN. Man's access to health services in primary care. Rev Fund Care Online. 2017 abr/jun;9(2):302-8. DOI: http:// dx.doi.org/10.9789/2175-5361.2017.v9i2.302-308

3. Xavier SQ, Ceolin T, Echevarría-Guanilo ME, Mendieta MC. Group of education in health: closeness of men to a primary health care center.
J res fundam care. 2015;7(2):2372-82. DOI: 10.9789/2175-5361.2015.v7i2.2372-2382

4. Vieira KLD, Gomes VLO, Borba MR, Costa CFS. Atendimento da população masculina em unidade básica saúde da família: motivos para a (não) procura. Esc Anna Nery. 2013 mar;17(1):120-7. DOI: http://dx.doi.org/10.1590/ S1414-81452013000100017

5. Lopez SB, Moreira MCN. Políticas nacionais de atenção integral à saúde de adolescentes e jovens e à saúde do homem: interlocuções políticas e masculinidade. Ciênc saúde coletiva. 2013 mar;18(3):743-52. DOI: http://dx.doi.org/10.1590/ S1413-81232013000300020

6. Brasil. Ministério da Saúde. Secretaria de Atenção à Saúde. Departamento de Ações Programáticas e Estratégicas. Política Nacional de Atenção Integral à Saúde do Homem: princípios e diretrizes. Brasília, DF; 2009. (Série B. Textos Básicos de Saúde).

7. Orlandi EP. Análise de discurso: princípios e procedimentos. 11a ed. Campinas: Pontes; 2013.

8. Brasil. Conselho Nacional de Saúde. Resolução $\mathrm{n}^{\mathrm{o}}$ 466, de 12 de dezembro de 2012. Aprova as diretrizes e normas regulamentadoras de pesquisas envolvendo seres humanos. Brasília, DF; 2012.

9. Carvalho FPB, Silva SKN, Oliveira LC, Fernandes ACL, Solano LC, Barreto ELF. Conhecimento acerca da Política Nacional de Atenção Integral à Saúde do homem na Estratégia de Saúde da Família. Rev APS [Internet]. 2013 [cited 2018 Jun 4];16(4):386-92. Available from: https://aps.ufjf.emnuvens.com.br/ aps/article/view/1977/761

10. Brasil. Ministério da Saúde. Portaria no 2.436 , de 21 de setembro de 2017. Aprova a Política Nacional de Atenção Básica, estabelecendo a revisão de diretrizes para a organização da Atenção Básica, no âmbito do Sistema Único de Saúde (SUS) [Internet]. Brasília, DF; 2017. [cited 2018 Jun 10]. Available from: http://bvsms.saude.gov.br/bvs/ saudelegis/gm/2017/prt2436_22_09_2017.html

11. Fertonani HP, Pires DEP, Biff D, Scherer MDA. The health care model: concepts and challenges for primary health care in Brazil. Ciênc saúde coletiva. 2015 June;20(6):1869-78. DOI: http://dx.doi. org/10.1590/1413-81232015206.13272014

12. Junges JR, Barbiani R, Fernandes RBP, Prudente J, Schaefer R, Kolling V. O discurso dos profissionais sobre a demanda e a humanização. Saude soc. 2012 Sep;21(3):686-97. DOI: http://dx.doi.org/10.1590/ S0104-12902012000300014 
13. Moreira RLSF, Fontes WD, Barboza TM. Difficulties of the man in primary healthcare: the speech of nurses. Esc Anna Nery. 2014 Dec;18(4):615-21. DOI: http://dx.doi.org/10.5935/1414-8145.20140087

14. Bispo A, Dias AB, Pereira A. Seeking for health care: issues of gender and race among black contributors from a university. J res: fundam care. Online. 2015 [cited 2017 June 19];7(1):1856-66. Available from: http://www.seer.unirio.br/index. $\mathrm{php/cuidadofundamental/article/view/1782/}$ pdf_1416

15. Carvalho FPB, Silva SKN, Oliveira LC, Fernandes ACL, Solano LC, Barreto ELF. Conhecimento acerca da Política Nacional de Atenção Integral à Saúde do Homem na Estratégia de Saúde da Família. Rev APS [Internet]. 2013 [cited 2017 Nov 21];16(4):38692. Available from: https://aps.ufjf.emnuvens.com. br/aps/article/view/1977/761

16. Silva DM, Souza TO, Lima MV, Yarid SD, Sena ELS. Acessibilidade do homem aos serviços da atenção básica: uma aproximação com a bioética da proteção. Cogitare Enferm [Internet]. 2013 [cited
2017 Nov 21];18(3):573-8. Available from: https:// revistas.ufpr.br/cogitare/article/view/46361/27851

17. Pereira LP, Nery AA. Planning, management and actions of men's health in the family health strategy. Esc Anna Nery. 2014 Dec;18(4):635-43. DOI: http:// dx.doi.org/10.5935/1414-8145.20140090

18. Sousa AR, Queiroz AM, Florencio RMS, Portela PP, Fernandes JD, Pereira A. Homens nos serviços de atenção básica à saúde: repercussões da construção social das masculinidades. Rev baiana enferm. 2016 jul/set;30(3):1-10. DOI: 10.18471/rbe. v30i3.16054

19. Martins AM, Malamut BS. Análise do discurso da Política Nacional de Atenção Integral à Saúde do Homem. Saude soc. 2013 June;22(2):429-40. DOI: http://dx.doi.org/10.1590/ S0104-12902013000200014

Recebido: 30 de janeiro de 2019 Aprovado: 5 de setembro de 2019 Publicado: 16 de dezembro de 2019

A Revista Baiana de Enfermagem utiliza a Licença Creative Commons - Atribuição-NãoComercial 4.0 Internacional. https://creativecommons.org/licenses/by-nc/4.0/ Este artigo é de acesso aberto distribuído sob os termos da Licença Creative Commons (CC BY-NC). Esta licença permite que outros remixem, adaptem e criem a partir do seu trabalho para fins não comerciais. Embora os novos trabalhos tenham de lhe atribuir o devido crédito e não possam ser usados para fins comerciais, os usuários não têm de licenciar esses trabalhos derivados sob os mesmos termos. 